\title{
Smart architecture contribution to achieving sustainable architecture realization
}

\author{
M. Ghorbanzadeh ${ }^{1} \&$ A. Nezami ${ }^{2}$ \\ ${ }^{1}$ Bojnord University, Iran \\ ${ }^{2}$ P.P.S co., Iran
}

\begin{abstract}
In this article we consider the ideologies that affect modern human life and smart architecture contribution used as tools to enable those ideologies. It is considered that the technological impact on human life is undeniable but, as well as making use of the technology environment, consideration is really required. Therefore, this study explores the role of smart structures and materials to create new buildings with sustainable architecture.

First, such terms as green architecture and sustainable architecture are identified. Then, using smart technology in buildings and what it would be like, are defined. Various smartness used in the buildings, their outcomes, performances and roles are evaluated. Smart buildings' role in sustainable architecture is explained.

Keywords: smart architecture, sustainable architecture, green buildings, building technologies, smart materials, ecological design, sensors, actuators, biomimetics, efficient design.
\end{abstract}

\section{Introduction}

Nature always inspires man in engineering. Smart buildings and materials are not exceptional for this rule. Zuk and Clark in their book "Kinetic architecture" suggest that "life is a kind of movement, which begins from a single cell to the most complex organisms. Movement, dynamism, changeability and compatibility are signs of life. Additionally, survival depends on these factors. It implies that they can feed biological process, remedy its pains, restore it, and 
finally adjust the biological mass with its environment." In fact, this ideology represents the beginning of smart buildings plan. The main goal is to facilitate such biological functions as sensing, controlling, and reacting by what is called smart building. This exact idea is the first motivation and development factor in the new path, called "smart buildings".

Building Smart Alliance, a council of the National Institute of Building Sciences, define the smart building as follows: "smart building with its four components: systems, structures, services and management as well as their interactions, creates an efficient and low cost environment. The single common characteristic of all smart buildings is a design such that it responses to changing environment with a low cost and efficient way."

The multitask components of a smart structure take the responsibility of diagnosis, control and operation processes. In fact, smart structures resembles human body metabolism. Biological systems are a kind of smart structure that imitates nature. These systems are smart structures as well as economic which are able to be used as a main reference for smart structure design. We will discuss the details later.

Smart materials with two functionalities of sensing and system operation are used to build a smart structure. In the other words, smart structure reacts properly to any changing in the environment including changing in its own circumstances. Such a structure is properly and usefully predesigned. Proper reaction implies that two or more motives are received but based on the design there will be only one reaction.

Smartness involves optimum behavior in different conditions. Though some smart structures were designed in the long past, what makes present activities more interesting is the high level of development in materials used, information technology, measurement instruments, sensors, operators, signal processing, nanotechnology, cybernetics, artificial intelligence and biomimetics [1].

Smartness in building is shown in these fields: a) building management systems such as heating and cooling control systems, lighting control system, fire alarm and fire fighting system, emergency power control system, earthquake alarm system, etc.; b) monitoring systems such as closed circuit system of digital cameras; c) access control system such as door automatic open-close system and anti thief system; d) communications systems: TV and satellite signal distributor system; e) safety structure systems such as absorption tools, warning tools, etc.

We seek to address smart structures in this paper. Smart structures provide flexibility and adjustability for the building in order to be aligned with its environment. Inevitably, regarding to environment concerns and higher concern for sustainable architecture in modern world, smart buildings take an efficient step towards sustainability by improving in construction process and proper impact on building maintenance and by lowering the energy and cost of reconstruction.

We address smart buildings function to provide a healthier environment and higher efficiency for building based on sustainable architecture. 


\section{Smart structures formation basics}

The smart structure idea was first addressed early 1980s [2]. A smart building was first defined as a building which makes use of new technologies but later (1991), flexibility was added, which means that the building is able to change in function. Then environmental considerations and economical conditions of users were added to the definition. In 1998, Kroner suggested that smartness was evaluated based on some criteria: building which is equipped with electronics to provide a convenient place for the inhabitants [3]. Arkin and Paciuk modified the above definition as smartness doesn't mean to be content with only specific technology in order to improve some functional systems (as lighting or air conditioning) but it addresses whole systems integration [4].

In summary, smart building evolution was as follows: 1981-1985 (old view): smartness is seen as building management, communication and automation with help of new technology to provide convenient office affairs. 1986-1991 (guided view): smartness in building management, office affair automation, communication and providing proper reaction to organizational change by means of new technology. 1992-1995 (advanced view): smartness in building management, environment management and management over economical fields in order to provide proper and efficient as well as supportable reaction to economical change. Since 1995 (wholeness view): smartness provides conditions to use all before mentioned fields, including followings:

- Economical field: lower cost, high productivity, lower dangers.

- Environmental field: lower gas pollutants and improvement in energy use.

- Social field: higher quality life and healthier building inhabitants.

\section{Sustainable development, sustainable architecture}

The UN conference on sustainable development in New York (1987) gave the following definition: The development which responds to human demands without destroying potentials, may be used to respond to human future demands [5].

Based on the above definition, the final purpose of sustainable architecture is to provide health and convenience of both present and future generations. The definition attracts one sided and immoderate minds of builders. Considering the future generation interests represents social position establishment for such discussions among different nations so that sustainable development is put into the agenda for governments (even the third world) as well as international conferences.

Certainly, any effort to protect and sustain Earth is acceptable. Smart building, specially, smart structure by use of technology has transformed present architecture definitions and will remove a lot of limitations for sustainable architecture. 


\subsection{Green building and ecological design in architecture}

According to Ken Yeang:

- Ecological design recognizes nature and environment restoration and respects its borders.

- Ecological design seeks to repair and maintain ecosystems.

- Ecological design seeks symbiosis between manmade systems and natural systems.

- $\quad$ Ecological design must gain a predicting view [6].

As you see, ecological design must be closer to natural systems as much as possible, so it must gain higher level of smartness, never violating natural ecosystem rule. An unelectable element in design of a building is consideration of the building as a living organism, effective on nature as well as an inter structure ecologic goal.

If architects have enough knowledge of smart buildings, they can remove the negative effect of building on environment ecology and it will be decreased very much.

\section{Inherent smartness and artificial smartness}

Three main components involve how to live: man, nature and machine. Machines are functioning biologically by improving their smartness. As this phenomenon advances, the distinction between inherent and artificial smartness will be more ambiguous. Smart artifacts will dominate, will adjust, will repair themselves and will be developed.

If smart structures are to gain comprehension, learning and decision making ability should be provided for them. It involves data collection.

The human brain is smarter than computer, because man can process a lot of data simultaneously. A brain bears $10^{11}$ neurons; the human brain is the most intelligent model of data processing.

Artificial neural networks (NNs) simulate the human brain model. They can dynamically and simultaneously learn system structure without previous knowledge. Artificial neural networks (NNs) involve a large number of processing elements (PEs) and are designed to use of a considerable combined behaviors without relying on each element behavior [1].

\section{Smartly designed structures}

The terms such as "smart", "comprehensive", "compatible" and other terms are used for explaining and grouping smart buildings and materials, representing the fact that the given system has sensor, and control and measuring hardware. According to one of the proposed definitions for smart materials and smart buildings, they have compatibility with extrinsic actuators such as forces because of their inherent smartness.

So, smart building components integrally and logically adjust with their environment. 
Smart configuration addresses natural loads in natural conditions. If necessary, operator systems encounter with abnormal loads actively. For example, smart structure mast be able to operate actively when earthquake occurs in seismic zones like Iran.

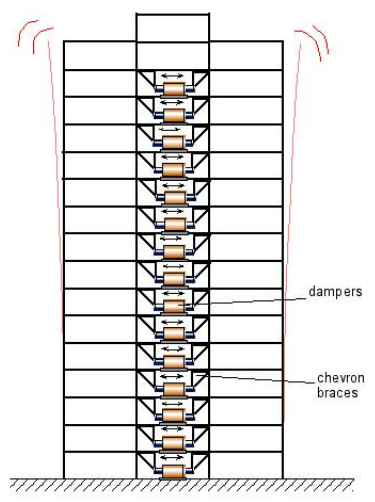

Figure 1: Inclusion of dampers in this high building provides its stability when an earthquake occurs. Dampers are filled with magneto rheological fluid (MRF). The fluid is solidified when facing magnetic forces but it restores its fluidity when vibration occurs. So it remains stable during quakes. The picture shows how the dampers operate during earthquake.

It should be noted that dampers are not only suitable for critical events (abnormal loads, such as earthquakes), but also they are used for resistance against normal, long term loads, corrosion and other parameters of oldness which endanger even safety. If we include widely sensors and permanent monitoring systems into the design, it could be possible to repair on time, decrease the costs and ensure higher safety.

\section{Smart structures evolution}

Man made structure evolution paths are as follows:

- Actively smart structures (sensor + feedback + enhanced actuator action).

- Very smart structures (sensor + feedback + enhanced actuator action + one or more other biomimetic features).

- Intelligent structures (actively smart structures endowed with a learning feature, so that the degree of smartness increases with experience).

- Wise structures (moral and ethical decisions).

- Consciousness in smart structures.

- Collective consciousness. The Internet is already playing the role of a collective consciousness for the planet earth, and much more is still to come. 
- Man-machine integration. Immortality through repeated repair or replacement of worn out or unserviceable parts (both animate and inanimate)[1].

Of man-made items, the main source is the human brain and it involves machines compatibility with the human nervous system. The properties of an intelligent man's brain may be summarized as follows:

- Perception of location and conception of space;

- Knowledge of past and having imagination and dream;

- Ability to focus on a significant job;

- Ability to predict various event and to plan for future;

- Decision making;

- Emotions and feelings.

Most robots are designed to provide at least one of these properties. Emotions and feelings modeling in robots may seem unachievable dream.

\section{Smart structure's behavior}

There are two kind of smartness in structures: closed-circuit and open-circuit. Closed-circuit smart structure percepts changes and distinguishes the nature of problem, initiates to decrease the severity of problem and saves the related data to refer to them later [1]. Open-circuit smart structure is designed to be integrated more only if needed, otherwise it functions normally [1].

Smart structure is a combination of sensor, actuator and control system. In addition to using sensors and actuators with good performance, a more important part of smarter structures is the development of optimum control algorithm to lead actuators for better performance after the sensor sense the changes.

Adaptronic structures are another term for smart structures. Rogers clarifies the nature of adaptronic structure design: "the main assumption for adaptronic structures is that they are designed for a proper and optional purpose and they must be able to transfer the energy and their behavior in order to create a set of performances..." It implies that smart structures can help architecture and create flexibility in architectural spaces.

\subsection{Biomimetics}

Structures or biological systems are the smartest or the most cost effective ones. Figure 2 shows main configuration of a biological system and its components are: sensors (nerves), actuators (muscles), distributed control center (brain) and host material (body). Of course, a power source is needed.

Living system sense changes in the environment. Then sensors data are sent to the brain (control center). Living organism needs to have a goal (for example, survival or stability). The brain sends signals to muscles or actuators based on the given goal in order some essential actions are performed. For example, if it exceeds a predetermined value in the environment there is a continuous feedback between sensors, actuators and decision making center. 
Smart structures more or less imitate biological systems so that they can be defined as structures with properties close to or possibly above biological structures.

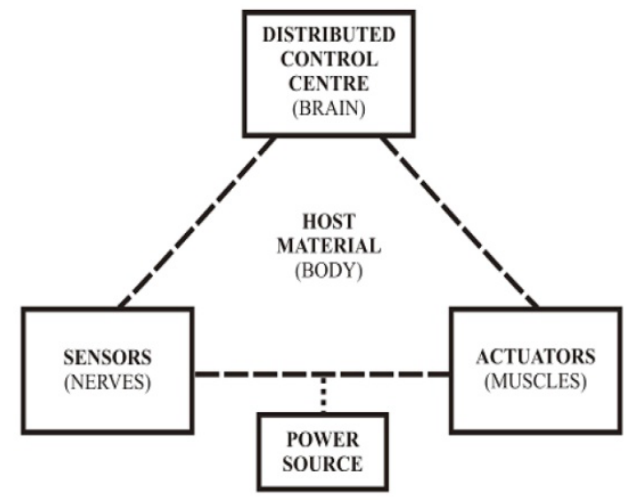

Figure 2: $\quad$ Main configuration needed for a living system [1].

As mentioned above, biological structures common properties include: sensors, actuators, adoptability, self repairing, self replication or reproduction. Smart structure designers try to provide these properties with lower cost. Very smart structure benefits from most of these properties. Future smart structure may be so advanced that could design themselves. Smart structures copy biological structures and make use of online sensors, actuators and microprocessors. They try substitute online adaptability requires various factors: one of which is how materials of structure so called smart materials react to intrinsic and extrinsic forces. Smart materials I.Q. is evaluated according how they reaction rapidly to the motives in environment.

Smart materials can be classified in to three groups: a) single-phased material; b) double-phased material; c) smart buildings.

Ferroic materials and those which are based on few anomalous rules, and related to phase change phenomenon, belong to the first group. In fact, the third group is a combination of sensor, actuator and a control system, imitating the body metabolism and it is designed to do the tasks of adoptability to change in environment and self repairmen. These three levels cover general definition of smart structure and material.

\subsection{Sensors}

As it is shown in figure 2, sensing is essential in smart structure. There are various outputs for sensor in biological systems. But electrical signal is the most convenient sensor output for smart structure. So, sensors convert a form of input energy into electrical signal. Optical fibres are commonly used for sensors in smart structures. 


\subsection{Actuators}

Actuators like sensor are essential parts for most smart structures. Actuator transduces other forms of energy into controllable mechanical movement. They are made of ferroic materials.

\section{Future of smart structures}

We will witness the combination of four ultra technologies:

- Advanced material

- Nanotechnology

- Information technology

- Bio technology

Nanotechnology is connected properly with smart structures. The purpose is to manipulate individual molecules and atoms and place them where they should be or to motivate them to do that integrated [1].

With nanotechnology, an object, a building, in different place and time, behaves differently and its behavior is well field-oriented or performanceoriented. They will be able to adopt smartly with temperatures, weather conditions, energy consumption and other climate conditions, geological change and load change. All these are included as data in computer programs for building or structure to be executed if needed to achieve an adoptive and convenient environment [7].

Our machines will be advanced and inherent-artificial smarts distinction as well as living-nonliving or nature-technology distinctions will be decreased.

\section{How smart structure helps sustainable architecture and green architecture}

Green and sustainable architecture goals are classified into three fields:

1. Environmental goals: higher quality environment, using less transformable and more restorable materials.

2. Economical goals: reduced costs, reduced energy consumption and convenient production and performance.

3. Social goals: attaining security and adoptability with environment [5].

The conditions of a building which will lead to the goals of green and sustainable architecture may be following in summary:

- Nontoxic materials which do not affect on environment.

- Efficiency in energy: construction process which consumes less energy.

- Quality and durability: higher quality building with longer time lasting.

- Designation for reuse and restore materials and systems [8].

Van Der Ryn and Calthrope (1986) in "sustainable societies", introduce sustainable environment as follows: A sustainable human environment provides minimal physical and psychological problems for its inhabitants. For example, disproportion between spaces and needs, demands or user behavior patterns, 
higher cost for required repair, replacement or maintenance, not meeting environment requirements, demanding minimal resources such as ground, water, soil and fuels (non-renewable) resulting minimal load on its environment [9].

Urban environment is expending and new construction methods are introduced. So, it is not surprising that construction industry has turned to be very enormous and it is very important in three dimensions: economical, social and environmental.

Table 1: $\quad$ Sustainable architecture profile.

\begin{tabular}{|c|c|c|}
\hline \multicolumn{3}{|c|}{ Meeting ecological requirements } \\
\hline Human health protection & $\begin{array}{l}\text { Environment } \\
\text { protection }\end{array}$ & $\begin{array}{l}\text { Resource protection } \\
\text { (energy/materials) }\end{array}$ \\
\hline \multicolumn{3}{|c|}{ In all stages of building life cycle } \\
\hline $\begin{array}{l}\text { During the end of building } \\
\text { function: } \\
\text { - During removing the } \\
\text { building } \\
\text { - During functional change } \\
\text { During building } \\
\text { demolition }\end{array}$ & $\begin{array}{l}\text { During use of } \\
\text { building } \\
\text { - In exploiting } \\
\text { - In maintenance } \\
\text { - In reconstruction } \\
\text { In rebuilding }\end{array}$ & $\begin{array}{l}\text { In building construction } \\
\text { process: } \\
\text { - During material collection } \\
\text { - During material production } \\
\text { - During structure } \\
\text { construction } \\
\text { During other stages of } \\
\text { construction }\end{array}$ \\
\hline
\end{tabular}

Today, commercial, public and residential buildings must meet multi aspect requirements: from resistance to fire, water flood, natural disasters and terrorist attacks, to energy efficiency, less environmental impact, providing access to web networks, as well as meeting the needs of elders and disables.

Quality of building directly affects human life quality. From an ecological viewpoint, the construction industry uses an enormous part of natural resources and produces very large amounts of wastes and pollution. In addition, this industry uses energy and produces destructive gases. Itu, Iso, Iec standards encourage smart buildings all over the world, including standards on efficient use of energy, ecological reforms, environmental performance and gas evaluation.

Designers, architects, engineers, industry owners, public authorities provide smart building development upon these standards. These international standards ensure not only safety requirements and high quality in buildings but also lead to develop new technologies in construction and making use of smart and sustainable buildings.

As mentioned above, smart buildings are designed to help man in economical, environmental and social fields. So, they are instruments for attaining sustainable design since they help sustainability concept both during construction and use of building and during the end of its functionality.

Sustainability depends on ecological protection plus all mentioned above:

1. Smart structure imitation from natural processes and systems, represents a kind of continuous adaption instead of one-phase design and construction and thus provides sustainability requirements. 
2. When smart structure uses building, reconstruction and maintenance, helps sustainability aspects. For example, sensors installation in buildings, provide continuous monitoring. Therefore failures and faults are diagnosed and are repaired very soon. Thus, safety increases and the costs decrease, both are related to sustainable architecture concept.

3. Smart structure concept helps architecture to provide flexible spaces for various usages. In fact, the ability to be reconstructed, replaced and change, makes smart structure an active and non-permanent one which is able to solve many architecture non-adaptability problems.

This study shows that smart structures can provide healthier buildings with higher efficiency and higher life quality for the inhabitants. According, it is expected that smart buildings turns to be the most important solution for improving human living condition and human environment and ultimately leading to green and its higher role in human life, as well as change of demands level.

\section{References}

[1] Wadhawan, V.K., Smart Structures and materials, Resonance, pp 27-28, 36, 38, 40, July 2002.

[2] Behzadi, B., Smart control systems in building, Abadi Mag., vol. 43, p.68, 2005

[3] Kroner, W.W., The new frontier: Intelligent architecture through intelligent design, futures, 9, vol. 21, no. 4, pp 319-333, August 1998.

[4] Arkin, H., Paciuk, M., Evaluating intelligent building according to level of service systems integration, Automation in construction, vol. 6, no. 516, pp 471-9, 1997.

[5] Ahmadi, f., sustainable architecture, Abadi Mag, vol. 40, 41, p. 95, 2004

[6] Yeang. K., The Green Skyscraper: The Basis for Designing Sustainable Intensive Buildings. Munich. London. New York. 1984.

[7] Abasalipour, S., Nano houses, the houses of future, Fine arts Mag., vol. 30, p. $86,2008$.

[8] http://www.green building supply.com

[9] Farhoodi, M., Sustainable architecture concept review, Architectural \& construction Mag., vol. 12, p. 39, 2007-2008. 